\title{
Long-Term Clinical Outcome according to Changes of Glomerular Filtration Rate in AMI Patients with Multivessel Disease after Percutaneous Coronary Intervention
}

\author{
Xiongyi Han ${ }^{\dagger}$, Liyan Bai ${ }^{\dagger}$, Myung Ho Jeong*, Dae Young Hyun, Kyung Hoon Cho, Yongcheol Kim, \\ Min Chul Kim, Doo Sun Sim, Young Joon Hong, Ju Han Kim, and Youngkeun Ahn
}

The Heart Center and Cardiovascular Convergence Research Center of Chonnam National University Hospital, Gwangju, Korea

Glomerular filtration rate (GFR) is an important indicator of renal failure. However, regarding delta GFR in acute myocardial infarction (AMI) is rare. In this study, it was examined whether the delta GFR had an adverse effect on outcomes in patients with AMI and multivessel disease (MVD). Among 13,105 consecutive patients enrolled in the Korea Acute Myocardial Infarction-National Institute of Health registry, 2619 with AMI and MVD who underwent percutaneous cardiac intervention (PCI) were assigned to the better delta GFR (group I, n=1432 [54.7\%]) or worse delta GFR (group II, n=1187 [45.3\%]) groups and followed for 3 or more years. The mean age of group I was lower than that of group II $(62.64 \pm 11.52$ years vs. $64.29 \pm 11.64$ years; $p<0.001)$. On multivariate analysis, delta GFR (hazard ratio, 1.50; 95\% confidence interval, 1.05-2.13; $\mathrm{p}=0.024)$ was a negative risk factor for adverse cardiac events. Age over 65 years $(\mathrm{p}<$ $0.001)$, history of MI ( $p=0.008)$, low hemoglobin $(p<0.001)$, high triglyceride $(p=0.008)$, low high-density lipoprotein cholesterol $(\mathrm{p}=0.002)$, and low left ventricular ejection fraction $(\mathrm{LVEF})(\mathrm{p}<0.001)$ were prognostic factors for major adverse cardiac events (MACE). In patients with a GFR $<60 \mathrm{~mL} / \mathrm{min} / 1.73 \mathrm{~m}^{2}$, mortality was increased by $0.9 \%$ in the multivessel PCI group and $0.7 \%$ in the IRA-only PCI group at the 1-year follow-up. According to the 3-year clinical follow-up analysis, prognosis was better in better delta GFR patients with AMI and MVD who underwent PCI than in worse delta GFR patients.

Key Words: Myocardial Infarction; Glomerular Filtration Rate; Percutaneous Coronary Intervention

This is an Open Access article distributed under the terms of the Creative Commons Attribution Non-Commercial License (http://creativecommons.org/licenses/by-nc/4.0) which permits unrestricted non-commercial use, distribution, and reproduction in any medium, provided the original work is properly cited.

\section{Article History:}

Received January 20, 2020

Revised February 20, 2020

Accepted February 25, 2020

\section{Corresponding Author:}

Myung Ho Jeong

Principal Investigator of Korea Acute Myocardial Infarction Registry, Heart Research Center, Chonnam National University Hospital, 671 Jaebong-ro, Dong-gu, Gwangju 61469, Korea Tel: +82-62-220-6243 Fax: +82-62-228-7174 E-mail: myungho@chollian.net

${ }^{\dagger}$ These authors contributed equally to this work.

\section{INTRODUCTION}

Patients with chronic kidney disease (CKD) exhibit accelerated atherosclerosis progression and higher cardiovascular morbidity and mortality rates. ${ }^{1,2}$ And the glomerular filtration rate (GFR) is an important indicator for diagnosing CKD and renal injury in real-world practice. ${ }^{3}$ Additional, acute coronary artery syndrome (ACS) is the most common reason for death, ${ }^{4}$ and ST-elevation myocardial infarction (STEMI) and non-ST-elevation myocardial infarction are increasingly becoming the focus of researchers. With technological developments, we can treat more complex ACS patients with multivessel disease (MVD). Among them, MVD patients comprise approximately $50 \% .^{5}$ The
Korean Acute Myocardial Infarction Registry-National Institutes of Health (KAMIR-NIH) study demonstrated that multivessel lesion patients comprise approximately $55 \%$ of patients. ${ }^{6}$ The outcomes of MVD patients is worse than that of single vessel disease patients. There are multiple options for treatment, each patient is cared differently, and the number of MVD patients is growing in the real world. This study sought to better understand whether kidney injury has changed between the two percutaneous coronary intervention (PCI) methods (Multivessel PCI and IRA-only PCI) in MVD with acute myocardial infarction (AMI).

Although studies of GFR in patients with MVD are plentiful, those on delta GFR and MVD are rare. Delta GFR is the percentage value converted from GFR, it can be used 
as an indicator of improved or impaired renal function, but is uncommonly used in general clinical practice. The delta GFR was calculated as the difference between current GFR and previous GFR. According to a previous study, delta GFR begins to decline at age 60 years in healthy men. ${ }^{7}$ Research on delta GFR in terms of AMI and MVD is currently unavailable. Therefore, here we aimed to determine if delta GFR has an important clinical effect on patients with AMI with MVD.

\section{MATERIALS AND METHODS}

\section{Study population and design}

The study population was derived from the KAMIR-NIH data from between October 2011 and December 2015. The KAMIR-NIH is a prospective, open, online, multi-center registry from 20 tertiary hospitals with resources to perform PCI in Korea that was set up to capture real-life treatment practices and outcomes of patients with AMI. ${ }^{8}$ A total of 13,105 patients are enrolled in the KAMIR-NIH registry. Among them, we excluded patients who were lost to follow-up over 3 years $(n=197)$, cases of failed or unattempted percutaneous coronary interventions (PCI) $(n=356)$, and unclear data on creatinine level or loss of creatinine at the 1-year follow-up $(\mathrm{n}=5793)$, patients with single-vessel disease $(n=4131)$ and acute kidney injury $(n=9)$. We selected all patients who underwent successful PCI with completed follow-up regarding creatinine levels at 1 year and complete 3-year data regarding outcomes. Finally, we selected 2619 patients who underwent PCI with AMI and MVD. The 2619 patients were divided into two groups based on the delta GFR value. In the better delta GFR group ( $n=1432)$, the complete 1-year data on creatinine levels were collected and the delta GFR was higher than 0\% (group I). In the worse delta GFR group ( $n=1187)$, the delta GFR was less than $0 \%$ at the 1-year follow-up (group II) (Fig. 1). All patients completed the 3-year interview, chart review, or phone call on outcomes. The study design was approved by the institutional ethics committee.

\section{Definition}

To determine the GFR, we used the modification of diet in renal disease (MDRD) study equation [GFR: female= $186 \times(\text { creatinine })^{-1.154} \times(\text { age })^{-0.203} \times 0.742 ;$ male $=186 \times($ creatinine $\left.)^{-1.154} \times(\text { age })^{-0.203}\left(\mathrm{~mL} / \mathrm{min} / 1.73 \mathrm{~m}^{2}\right)\right] .^{9}$ The delta GFR (\%) was calculated as the difference between current GFR (1 year later) and previous GFR (1 year ago) [100× (current GFR - previous GFR)/previous GFR, (\%)] (Fig. 1). ${ }^{7}$ This formula was used for all the selected patients, and the basal serum creatinine values were calculated on admission.

\section{Study endpoint}

The endpoint of the study was the occurrence of clinical events within 3 years defined as all-cause death (cardiac and non-cardiac), recurrent myocardial infarction (re-MI), repeat PCI [target lesion revascularization (TLR), target vessel revascularization (TVR), coronary artery bypass graft (CABG), major adverse cardiac events (MACE: allcause death, re-MI, re-PCI, and CABG)]. Whether delta GFR is a risk factor for predicting the adverse clinical events was also determined. The second endpoint was observed as the predictor of the GFR less than $60 \mathrm{~mL} / \mathrm{min} / 1.73 \mathrm{~m}^{2}$ after

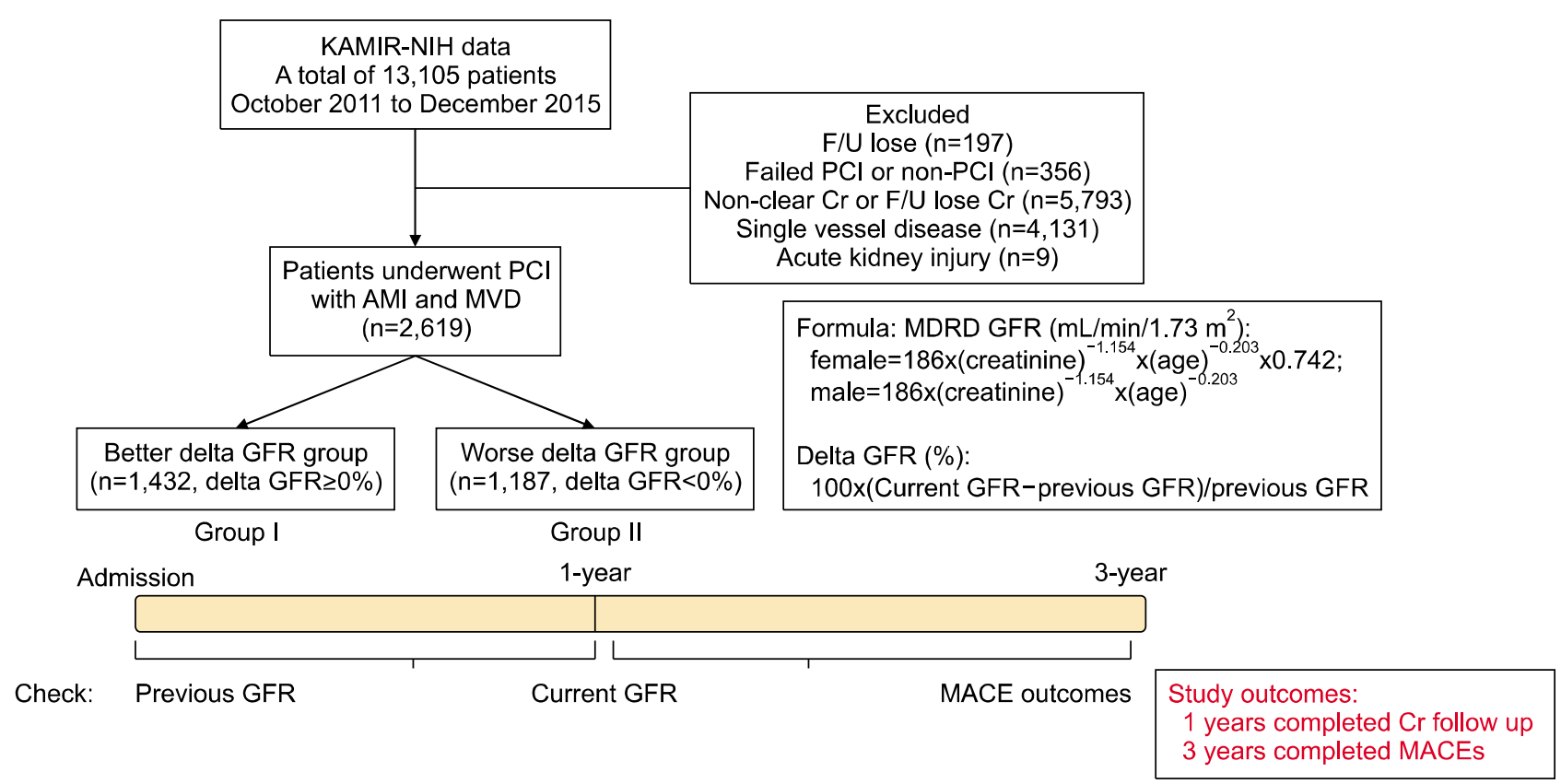

FIG. 1. Flow chart of the study patients. AMI: acute myocardial infarction, Cr: creatinine, F/U: follow-up, GFR: glomerular filtration rate, KAMIR-NIH: Korean Acute Myocardial Infarction Registry - National Institutes of Health, MACE: major adverse cardiac events, MDRD: modification of diet in renal disease, PCI: percutaneous coronary intervention. 
1 year. The third endpoint was whether the PCI procedure (Multivessel PCI vs. IRA-only PCI) affected the GFR after 1 year in patients with MVD.

\section{Statistical analysis}

All continuous variables are expressed as mean \pm standard deviation (SD). All categorical variables are reported as number and percentage. For continuous variables, the data were compared using the unpaired t-test or MannWhitney $\mathrm{U}$ test as appropriate. The categorical variables were analyzed using the chi-square test or Fisher's exact test. To adjust for more accurate results, we tested all available variables that could be of potential relevance, such as baseline clinical, laboratory, and medication factors. To investigate intergroup differences in terms of survival, the risk of MACE was assessed for the two groups using the Kaplan-Meier method. We used the Cox proportional hazards regression model to regress survival on an indicator variable denoting and evaluated the hazard ratios of the clinical outcomes to compare the two groups. To identify the significant predictors of MACE according to delta GFR, we screened for all predictors that might affect prognosis and subjected each to modeling. We entered significant variables with $\mathrm{p}$ values $<0.05$ on univariate analysis into the multivariate Cox regression model. For example, lower delta GFR $(<0 \%)$, old age ( $\geq 65$ years), male sex, high heart rate ( $>100$, beat/min), hypertension, low systolic blood pressure $(\mathrm{SBP}<90, \mathrm{mmHg})$, high body mass index $(\mathrm{BMI})\left(>25, \mathrm{~kg} / \mathrm{m}^{2}\right)$, diabetes mellitus and dyslipidemia, history of heart failure, MI, dyspnea ,angina or typical chest pain, low left ventricular ejection fractions (LVEFs $<40 \%$ ), high Killip classes (III/IV), smoking, low hemoglobin $(<10$, g/dL), high triglycerides ( $\geq 150, \mathrm{mg} / \mathrm{dL})$, low high-density lipoprotein (HDL) cholesterol ( $\leq 40, \mathrm{mg} / \mathrm{dL})$ and high low-density lipoprotein (LDL) cholesterol ( $\geq 70, \mathrm{mg} / \mathrm{dL})$ and high HbA1c $(>6.5 \%)$, American College of Cardiology/American Heart Association (ACC/AHA) type B2/C lesion, bad final thrombolysis in myocardial infarction (TIMI) flow (0/1) and drug-eluting stents (DES) implanted, and multivessel PCI. In the adjusted survival analysis, the hazard ratios (HR) and $95 \%$ confidence intervals (CI) between the two groups were obtained by multivariate analysis using Cox regression analysis.

All statistical analyses were performed using IBM-SPSS Statistics for Windows software (ver. 25.0; SPSS Inc., Chicago, IL, USA). All analyses were two-tailed, and p values $<0.05$ was considered significant.

\section{RESULTS}

\section{Baseline and laboratory findings}

A total of 2619 patients with AMI and MVD who underwent PCI were enrolled in the final study population. The better delta GFR group (group I) and worse delta GFR group (group II) included 1432 (54.7\%) and 1187 (45.3\%) patients, respectively. The mean age of group I was lower than that of group II $(62.64 \pm 11.52$ years vs. $64.29 \pm 11.64$ years, $\mathrm{p}<0.001$ ), and $44.0 \%$ and $51.6 \%$ of the patients were over 65 years of age, respectively. The mean SBP and diastolic blood pressure (DBP) were lower in group I than in group II ( $130.14 \pm 29.66$ vs. $134.30 \pm 28.36, \mathrm{p}<0.001 ; 78.06 \pm$ 18.48 vs. $80.67 \pm 16.53, \mathrm{p}<0.001$; respectively). In contrast, more patients in group I than in group II had Killip class III/IV disease. The mean creatinine level was higher in group I than in group II $(1.20 \pm 1.15 \mathrm{mg} / \mathrm{dL}$ vs. $0.96 \pm 0.75 \mathrm{mg} / \mathrm{dL}$, $\mathrm{p}<0.001)$. However, the 1 -year mean creatinine level was lower in group I than in group II $(1.01 \pm 0.83 \mathrm{mg} / \mathrm{dL}$ vs. $1.26 \pm 1.05 \mathrm{mg} / \mathrm{dL}, \mathrm{p}<0.001)$. Therefore, the mean GFR in group I was higher than that in group II $(77.81 \pm 26.32 \mathrm{~mL} /$ $\mathrm{min} / 1.73 \mathrm{~m}^{2}$ vs. $\left.96.51 \pm 36.25 \mathrm{~mL} / \mathrm{min} / 1.73 \mathrm{~m}^{2}, \mathrm{p}<0.001\right)$, as was the 1-year mean GFR $\left(91.03 \pm 41.42 \mathrm{~mL} / \mathrm{min} / 1.73 \mathrm{~m}^{2} \mathrm{vs}\right.$. $\left.72.89 \pm 25.83 \mathrm{~mL} / \mathrm{min} / 1.73 \mathrm{~m}^{2}, \mathrm{p}<0.001\right)$. Conversely, the mean white blood cell count and glucose level were higher in group I than in group II and the mean P2Y12 reaction unit was lower in group I than in group II. Intergroup differences in the other remaining laboratory indicators were insignificant (Table 1).

\section{Characteristics of the coronary angiography and pre- scribed medication}

In terms of coronary angiography, a lower number of left anterior descending (LAD) arteries (39.5\% vs. $44.7 \%$ ) were examined in group I than in group II, while more right coronary arteries (RCA) ( $41.3 \%$ vs. $35.5 \%)$ were examined in group I than in group II ( $\mathrm{p}=0.007)$, while similar numbers of left circumflex (LCX) arteries (19.1\% vs. $19.9 \%)$ were examined. Multivessel PCI was performed at similar frequencies in the two groups [531 (37.1\%) vs. $436(36.7 \%)$ ], and over $98 \%$ patients underwent the placement of DES. However, there were more STEMI patients in group I than in group II [767 (53.6\%) vs. $546(46.0 \%), \mathrm{p}<0.001]$. In terms of medical treatment, medications, including aspirin $(99.9 \%$ vs $99.9 \%)$, clopidogrel ( $75.1 \%$ vs. $73.6 \%)$, ticagrelor $(33.5 \%$ vs. $37.4 \%)$, prasugrel ( $10.5 \%$ vs. $11.7 \%)$, calcium channel antagonists (CCB) (7.3\% vs. $6.6 \%)$, angiotensin converting enzyme inhibitor/angiotensin II receptor blockers (ACEI/ ARB) ( $82.3 \%$ vs. $83.4 \%$ ), and beta-blockers ( $87.5 \%$ vs. $88.0 \%)$, were used at similar frequencies (Table 2).

\section{Clinical outcomes}

The univariate survival analysis is shown in Table 3. We selected a large number of factors to predict adverse factors. A Cox proportional hazard ratio analysis revealed that delta GFR (HR, 1.50; 95\% CI, 1.09-2.07; $\mathrm{p}=0.013$ ) was a risk factor for adverse cardiac events. However, age over 65 years, hypertension, diabetes mellitus, a high heart rate, a high Killip grade (III/IV), history of AMI, history of angina, dyspnea, typical chest pain, smoker status, low hemoglobin level, high triglyceride level, low HDL cholesterol, high LDL cholesterol, and low LVEF were independent predictive factors for adverse cardiac events. In the multivariate analysis, delta GFR (HR, 1.50; 95\% CI, 1.05-2.13; $\mathrm{p}=0.024$ ) was a risk factor for adverse cardiac events. Age over 65 years (HR, 2.20; 95\% CI, 1.46-3.31; $\mathrm{p}<0.001$ ), history of AMI (HR, 2.07; 95\% CI, 1.21-3.55; p=0.008), low he- 
TABLE 1. Baseline clinical and laboratory characteristics of patients in between two groups

\begin{tabular}{|c|c|c|c|}
\hline Variables & Delta GFR $\geq 0 \%$ (Group 1) $(\mathrm{n}=1432)$ & Delta GFR <0\% (Group 2) $(\mathrm{n}=1187)$ & $\mathrm{p}$ value \\
\hline \multicolumn{4}{|l|}{ Demographic } \\
\hline Age, mean (SD), year & $62.64 \pm 11.52$ & $64.29 \pm 11.64$ & $<0.001$ \\
\hline Age $\geq 65$ & $630(44.0)$ & $612(51.6)$ & $<0.001$ \\
\hline Male sex $(\%)$ & $1112(77.7)$ & $888(74.8)$ & 0.088 \\
\hline $\mathrm{BMI}$, mean (SD), $\mathrm{kg} / \mathrm{m}^{2}$ & $24.32 \pm 3.12$ & $24.04 \pm 3.10$ & 0.024 \\
\hline \multicolumn{4}{|l|}{ Clinical symptoms } \\
\hline Dyspnea & $347(24.2)$ & $265(22.3)$ & 0.251 \\
\hline Typical chest pain & $1269(88.6)$ & $1038(87.4)$ & 0.358 \\
\hline \multicolumn{4}{|l|}{ Cardiovascular risk factors $(\%)$} \\
\hline Hypertension & $780(54.5)$ & $640(53.9)$ & 0.778 \\
\hline Diabetes mellitus & $449(31.4)$ & $378(31.8)$ & 0.788 \\
\hline Dyslipidemia & $187(13.1)$ & $166(14.0)$ & 0.490 \\
\hline Current smoking & $883(61.7)$ & $696(58.6)$ & 0.115 \\
\hline \multicolumn{4}{|l|}{ Medical history (\%) } \\
\hline Myocardial infarction & $83(5.8)$ & $61(5.1)$ & 0.463 \\
\hline Heart failure & $11(0.8)$ & $7(0.6)$ & 0.588 \\
\hline Cerebrovascular accident & $83(5.8)$ & $68(5.7)$ & 0.904 \\
\hline \multicolumn{4}{|l|}{ Vital sign on admission } \\
\hline $\mathrm{SBP}$, mean (SD), mmHg & $130.14 \pm 29.66$ & $134.30 \pm 28.36$ & $<0.001$ \\
\hline $\mathrm{DBP}$, mean $(\mathrm{SD}), \mathrm{mmHg}$ & $78.06 \pm 18.48$ & $80.67 \pm 16.53$ & $<0.001$ \\
\hline HR, mean (SD), beat/min & $77.62 \pm 19.64$ & $78.13 \pm 17.39$ & 0.488 \\
\hline Killip class III/IV (\%) & $184(12.8)$ & $109(9.2)$ & 0.003 \\
\hline $\mathrm{LVEF},(\%)$ & $52.40 \pm 10.26$ & $51.94 \pm 10.83$ & 0.275 \\
\hline \multicolumn{4}{|l|}{ Laboratory findings } \\
\hline $\mathrm{WBC}, 10^{3} / \mathrm{uL}$ & $10.44 \pm 3.68$ & $10.01 \pm 3.37$ & 0.012 \\
\hline $\mathrm{Hb}, \mathrm{g} / \mathrm{dL}$ & $14.02 \pm 1.95$ & $13.92 \pm 2.01$ & 0.198 \\
\hline Total cholesterol, mg/dL & $181.71 \pm 42.95$ & $181.38 \pm 46.15$ & 0.851 \\
\hline Triglyceride, mg/dL & $144.03 \pm 121.75$ & $135.71 \pm 115.54$ & 0.085 \\
\hline HDL-cholesterol, mg/dL & $42.56 \pm 11.79$ & $42.29 \pm 11.29$ & 0.566 \\
\hline LDL-cholesterol, mg/dL & $114.29 \pm 37.67$ & $114.75 \pm 38.85$ & 0.769 \\
\hline Glucose & $174.11 \pm 83.23$ & $167.45 \pm 77.05$ & 0.038 \\
\hline Creatinine, $\mathrm{mg} / \mathrm{dL}$ & $1.20 \pm 1.15$ & $0.96 \pm 0.75$ & $<0.001$ \\
\hline 12-month $\mathrm{F} / \mathrm{U}$ creatinine, $\mathrm{mg} / \mathrm{dL}$ & $1.01 \pm 0.83$ & $1.26 \pm 1.05$ & $<0.001$ \\
\hline $\mathrm{GFR}, \mathrm{mL} / \mathrm{min} / 1.73 \mathrm{~m}^{2}$ & $77.81 \pm 26.32$ & $96.51 \pm 36.25$ & $<0.001$ \\
\hline 12-month F/U GFR, $\mathrm{mL} / \mathrm{min} / 1.73 \mathrm{~m}^{2}$ & $91.03 \pm 41.42$ & $72.89 \pm 25.83$ & $<0.001$ \\
\hline hs-CRP, mg/dL & $1.32 \pm 3.57$ & $1.34 \pm 3.31$ & 0.923 \\
\hline Peak CK-MB, ng/mL & $111.92 \pm 158.08$ & $119.24 \pm 135.91$ & 0.212 \\
\hline Peak Troponin-I, ng/mL & $44.41 \pm 74.34$ & $43.64 \pm 78.19$ & 0.813 \\
\hline $\mathrm{HbA1c},(\%)$ & $6.62 \pm 1.58$ & $6.63 \pm 1.56$ & 0.938 \\
\hline PRU & $177.91 \pm 106.72$ & $199.21 \pm 107.19$ & 0.007 \\
\hline ARU & $454.29 \pm 76.04$ & $461.12 \pm 71.93$ & 0.278 \\
\hline
\end{tabular}

Data are expressed as No. (\%) unless otherwise indicated.

ARU: aspirin reaction units, BMI: body mass index, CK: creatine kinase, DBP: diastolic blood pressure, DM: diabetes mellitus, F/U: follow up, GFR: glomerular filtration rate, HDL: high-density lipoprotein, HR: heart rate, Hb: hemoglobin, hs-CRP: high-sensitivity C-reactive protein, LDL: low-density lipoprotein, LVEF: left ventricular ejection fraction, PRU: P2Y12 reaction units, SBP: systolic blood pressure, STEMI: ST-elevation myocardial infarction, WBC: white blood cell.

moglobin (HR, 3.50; 95\% CI, 2.01-6.07; p<0.001), high triglyceride (HR, 0.53; 95\% CI, 0.33-0.85; $\mathrm{p}=0.008)$, low HDL cholesterol (HR, 1.76; 95\% CI, 1.22-2.53; $\mathrm{p}=0.002)$, and low LVEF (HR, 2.40; 95\% CI, 1.56-3.69; p<0.001) were prognostic factors for MACE.

The Cox regression unadjusted and adjusted survival analyses are shown in Table 4 . In the unadjusted model, all-cause death (HR, 2.15; 95\% CI, 1.33-3.48; $\mathrm{p}=0.002$ ), car- diac death (HR, 2.03; 95\% CI, 1.07-3.84; $\mathrm{p}=0.031$ ), and non-cardiac death (HR, 2.32; 95\% CI, 1.12-4.82; $\mathrm{p}=0.023$ ) rates were significantly better, and better delta GFR patients had significantly greater survival and MACE rates (HR, 1.50; 95\% CI, 1.09-2.07; $\mathrm{p}=0.013$ ). In the adjusted analysis, at the 3 -year clinical follow-up, 68 (4.7\%) patients in group I and $84(7.1 \%)$ patients in group II (HR, 1.50; $95 \%$ CI, 1.05-2.13; $\mathrm{p}=0.024$ ) had MACE. All-cause death oc- 
TABLE 2. Characteristics of coronary angiography and medication in in between two groups

\begin{tabular}{|c|c|c|c|}
\hline Variables & $\begin{array}{c}\text { Delta GFR } \\
\geq 0 \%(\text { Group } 1) \\
(\mathrm{n}=1432)\end{array}$ & $\begin{array}{c}\text { Delta GFR } \\
<0 \%(\text { Group } 2) \\
(\mathrm{n}=1187)\end{array}$ & $\mathrm{p}$ value \\
\hline Infarct-related artery (\%) & & & 0.007 \\
\hline Left anterior descending & $566(39.5)$ & $530(44.7)$ & \\
\hline Left circumflex & $274(19.1)$ & $236(19.9)$ & \\
\hline Right coronary & $592(41.3)$ & $421(35.5)$ & \\
\hline ACC/AHA B2/C lesion (\%) & ) $1246(87.0)$ & $1055(88.9)$ & 0.145 \\
\hline Multivessel PCI (\%) & $531(37.1)$ & $436(36.7)$ & 0.854 \\
\hline DES for IRA (\%) & $1415(98.8)$ & $1165(98.1)$ & 0.161 \\
\hline \multicolumn{4}{|l|}{ TIMI flow grade (\%) } \\
\hline Initial TIMI flow 0/1 & 787 & 649 & 0.885 \\
\hline Final TIMI flov & $1400(97.8)$ & 1157 & 0.624 \\
\hline \multicolumn{4}{|l|}{ Final diagnosis } \\
\hline STEMI & $767(53.6)$ & $546(46.0)$ & $<0.001$ \\
\hline \multicolumn{4}{|l|}{ Medical treatment (\%) } \\
\hline Aspirin & $1430(99.9)$ & $1186(99.9)$ & 0.676 \\
\hline \multicolumn{4}{|l|}{$\mathrm{P} 2 \mathrm{Y} 12$ receptor inhibitor } \\
\hline Clopidogrel & $1076(75.1)$ & $874(73.6)$ & 0.378 \\
\hline Ticagrelor & $379(33.5)$ & $330(37.4)$ & 0.067 \\
\hline Prasugrel & $151(10.5)$ & $139(11.7)$ & 0.344 \\
\hline Statin & $1364(95.3)$ & $1143(96.3)$ & 0.190 \\
\hline $\mathrm{ACEI} / \mathrm{AF}$ & $1179(82.3)$ & $990(83.4)$ & 0.469 \\
\hline Beta-blocker & $1253(87.5)$ & $1044(88.0)$ & 0.725 \\
\hline Calcium channel blocker & $105(7.3)$ & $78(6.6)$ & 0.447 \\
\hline
\end{tabular}

Data are expressed as No. (\%) unless otherwise indicated.

ACC: American College of Cardiology, AHA: American Heart Association, ACEI: angiotensin-converting enzyme inhibitor, ARB: angiotensin II receptor blocker, DES: dual eluting stent, GFR: glomerular filtration rate, IRA: infarct-related artery, PCI: percutaneous coronary intervention, STEMI: ST-elevation myocardial infarction, TIMI: thrombolysis in myocardial infarction.

curred in 26 (1.8\%) patients in group 1 and 46 (3.9\%) patients in group II (HR, 2.21; 95\% CI, 1.29-3.80; p=0.004). Cardiac death occurred in $15(1.0 \%)$ patients in group I and $25(2.1 \%)$ patients in group II (HR, 2.01; 95\% CI, 1.01-3.99; $\mathrm{p}=0.046)$. Non-cardiac death occurred in $11(0.8 \%)$ patients in group I and 21 (1.8\%) patients in group II (HR, 2.90; $95 \%$ CI, 1.16-7.27; $\mathrm{p}=0.023)$. Recurrent MI, repeat PCI and CABG did not differ significantly between groups I and II. In the Kaplan-Meier curves showed that the cumulative rate of MACEs and group I was lower than in the group II ( $4.7 \%$ vs. $7.1 \%$, log-rank, $\mathrm{p}=0.012$ ). Furthermore, the cumulative rate of all cause death and cardiac death and non-cardiac death found in group I was also lower than in the group II ( $1.8 \%$ vs. $3.9 \%$, log-rank, $\mathrm{p}=0.001$ and $0.8 \%$ vs. $1.8 \%$, log-rank, $\mathrm{p}=0.020$ and $1.0 \%$ vs. $2.1 \%$, log-rank, $\mathrm{p}=0.027$; respectively) (Fig. 2).

In the Cox regression multivariate analysis of the risk factors for a 1-year GFR $<60 \mathrm{~mL} / \mathrm{min} / 1.73 \mathrm{~m}^{2}$ (Table 5), age over 65 years (HR, 2.43; 95\% CI, 1.82-3.25; $\mathrm{p}<0.001)$, male sex (HR, 0.69; 95\% CI, 1.26-2.23; $\mathrm{p}=0.011)$, hypertension (HR, 1.69; 95\% CI, 1.26-2.23; $\mathrm{p}<0.001$ ), diabetes mellitus (HR, 1.57; 95\% CI, 1.19-2.08; $\mathrm{p}=0.002$ ), high Killip grade
(III/IV) (HR, 1.54; 95\% CI, 1.09-2.18; p=0.015), low hemoglobin (HR, 2.45; 95\% CI, 1.71-3.50; p<0.001), low LVEF (HR, 1.41; 95\% CI, 1.04-1.92; $\mathrm{p}=0.028)$, and slow TIMI flow $(0 / 1)(\mathrm{HR}, 0.74 ; 95 \% \mathrm{CI}, 0.58-0.94 ; \mathrm{p}=0.013)$ were risk factors for a low GFR $\left(60 \mathrm{~mL} / \mathrm{min} / 1.73 \mathrm{~m}^{2}\right)$ after 1 year.

\section{Renal function results by PCI strategy}

The renal function characteristics in multivessel versus IRA-only PCI are shown in Table 6. The creatinine, 1-year creatinine, GFR, and 1-year GFR values were similar between the two groups. Regarding a low GFR $(<60 \mathrm{~mL} / \mathrm{min} /$ $1.73 \mathrm{~m}^{2}$ ), 175 patients in the multivessel PCI group (18.1\%) and 305 patients in the IRA-only PCI group (18.5\%) had similar results $(\mathrm{p}=0.816)$. A low GFR $\left(<60 \mathrm{~mL} / \mathrm{min} / 1.73 \mathrm{~m}^{2}\right)$ was seen in 186 patients in the multivessel PCI group (19.2\%) and 318 patients in the IRA-only PCI group (19.2\%) at 1 year $(\mathrm{p}=0.993)$. The proportion of patients with a GFR $<60 \mathrm{~mL} / \mathrm{min} / 1.73 \mathrm{~m}^{2}$ increased by $0.9 \%$ in the multivessel PCI group and $0.7 \%$ in the IRA-only PCI group at 1 year. And last in the delta GFR, 67 patients in the multivessel PCI group (36.0\%) and 104 patients in the IRA-only PCI group $(32.7 \%)$ had similar results $(\mathrm{p}=0.448)$.

\section{DISCUSSION}

Here we found that better delta GFR patients in AMI with MVD who underwent successful PCI had a lower incidence of MACE than the worse delta GFR patients in terms of 3-year outcomes in the KAMIR-NIH prospective multicenter cohort study registry. The proportion of patients with a low GFR $\left(60 \mathrm{~mL} / \mathrm{min} / 1.73 \mathrm{~m}^{2}\right)$ was increased by $0.9 \%$ in the multivessel PCI group and $0.7 \%$ in the IRAonly PCI group at 1 year. In other words, the risk factors for the lower GFR $\left(60 \mathrm{~mL} / \mathrm{min} / 1.73 \mathrm{~m}^{2}\right)$ at 1 year included age over 65 years, male sex, hypertension, diabetes mellitus, high Killip class (III/IV), low hemoglobin, low LVEF, and TIMI flow $0 / 1$.

As an important indicator for the diagnosis of CKD, GFR is considered a major factor in heart failure and AMI outcome events. ${ }^{10}$ Approximately one-third of our patients had an estimated GFR suggestive of CKD, an incidence higher than that reported in previous cardiovascular trials. ${ }^{11,12}$ The results of the Valiant study found that the mortality rate of AMI patients gradually increased during 3-year long-term follow-up of GFR decline. ${ }^{13}$ The Global Registry of Acute Coronary Events study demonstrated that moderate renal insufficiency is an important independent predictor of hospital mortality and major bleeding episodes in patients admitted with any ACS diagnosis. ${ }^{14}$ GFR plays an important prognostic role in ACS patients, ${ }^{15,16}$ and creatinine has become the primary means of calculating GFR in most studies due to the MDRD study equation. It was seen in our study that patients with a decrease in GFR within 1 year had significantly more cardiac events than patients with an elevated GFR; this conclusion was similar to those of the above studies. Regardless of whether there was kidney failure or a low GFR before the AMI, the GFR 
TABLE 3. Univariate and multivariate analysis for predictors of MACE

\begin{tabular}{|c|c|c|c|c|}
\hline & \multicolumn{2}{|c|}{ Univariate analysis } & \multicolumn{2}{|c|}{ Multivariate analysis } \\
\hline & $\mathrm{HR}(95 \% \mathrm{CL})$ & $\mathrm{p}$ values & $\mathrm{HR}(95 \% \mathrm{CL})$ & $p$ values \\
\hline Delta GFR $<0 \%$ & $1.50(1.09-2.07)$ & 0.013 & $1.50(1.05-2.13)$ & 0.024 \\
\hline Age $\geq 65$ years & $2.86(2.01-4.06)$ & $<0.001$ & $2.20(1.46-3.31)$ & $<0.001$ \\
\hline Men & $0.86(0.60-1.24)$ & 0.429 & None & \\
\hline Hypertension & $1.83(1.30-2.56)$ & 0.001 & $1.27(0.87-1.86)$ & 0.222 \\
\hline Diabetes mellitus & $1.72(1.25-2.37)$ & 0.001 & $1.13(0.77-1.64)$ & 0.534 \\
\hline Dyslipidemia & $0.75(0.45-1.27)$ & 0.285 & None & \\
\hline $\mathrm{SBP}<90, \mathrm{mmHg}$ & $1.45(0.74-2.86)$ & 0.279 & None & \\
\hline Heart rate $>100$, beat $/ \mathrm{min}$ & $2.18(1.47-3.22)$ & $<0.001$ & $1.45(0.93-2.26)$ & 0.105 \\
\hline $\mathrm{BMI} \geq 25, \mathrm{~kg} / \mathrm{m}^{2}$ & $0.74(0.52-1.05)$ & 0.087 & None & \\
\hline Killip III/IV & $2.62(1.80-3.81)$ & $<0.001$ & $1.25(0.78-2.00)$ & 0.346 \\
\hline History MI & $2.28(1.38-3.77)$ & 0.001 & $2.07(1.21-3.55)$ & 0.008 \\
\hline History angina & $2.22(1.42-3.49)$ & 0.001 & $1.14(0.67-1.94)$ & 0.624 \\
\hline Dyspnea & $1.53(1.08-2.15)$ & 0.016 & $0.85(0.56-1.28)$ & 0.425 \\
\hline Typical chest pain & $0.51(0.34-0.76)$ & 0.001 & $0.75(0.48-1.18)$ & 0.221 \\
\hline Smoking & $0.71(0.52-0.98)$ & 0.037 & $1.04(0.71-1.52)$ & 0.836 \\
\hline $\mathrm{Hb}<10, \mathrm{~g} / \mathrm{dL}$ & $5.29(3.37-8.32)$ & $<0.001$ & $3.50(2.01-6.07)$ & $<0.001$ \\
\hline Triglyceride $\geq 150, \mathrm{mg} / \mathrm{dL}$ & $0.55(0.37-0.83)$ & 0.005 & $0.53(0.33-0.85)$ & 0.008 \\
\hline HDL-cholesterol $\leq 40, \mathrm{mg} / \mathrm{dL}$ & $1.73(1.24-2.40)$ & 0.001 & $1.76(1.22-2.53)$ & 0.002 \\
\hline LDL-cholesterol $\geq 70, \mathrm{mg} / \mathrm{dL}$ & $0.47(0.31-0.70)$ & $<0.001$ & $0.74(0.48-1.15)$ & 0.183 \\
\hline $\mathrm{HbA} 1 \mathrm{c}>6.5 \%$ & $0.92(0.61-1.37)$ & 0.683 & None & \\
\hline LVEF $<40 \%$ & $3.34(2.33-4.79)$ & $<0.001$ & $2.40(1.56-3.69)$ & $<0.001$ \\
\hline ACC/AHA B2/C lesion & $0.97(0.60-1.57)$ & 0.904 & None & \\
\hline Initial TIMI flow 0/1 & $0.79(0.58-1.09)$ & 0.146 & None & \\
\hline DES implantation & $0.44(0.18-1.06)$ & 0.067 & None & \\
\hline Multivessel PCI & $0.72(0.51-1.02)$ & 0.063 & None & \\
\hline
\end{tabular}

ACC: American College of Cardiology, AHA: American Heart Association, BMI: body mass index, Cl: confidence interval, DES: dual eluting stent, GFR: glomerular filtration rate, HR: hazard ratios, Hb: hemoglobin, HDL: high-density lipoprotein, LDL: low-density lipoprotein, LVEF: left ventricular ejection fraction, MI: myocardial infarction, PCI: percutaneous coronary intervention, SBP: systolic blood pressure, TIMI: thrombolysis in myocardial infarction.

TABLE 4. Unadjusted and adjusted clinical outcomes at 3 years between two groups

\begin{tabular}{|c|c|c|c|c|c|c|}
\hline Variables & $\begin{array}{c}\text { Delta GFR } \geq 0 \% \\
\text { (Group 1) }(\mathrm{n}=1432)\end{array}$ & $\begin{array}{c}\text { Delta GFR <0\% } \\
(\text { Group } 2)(\mathrm{n}=1187)\end{array}$ & $\begin{array}{l}\text { Unadjusted } \\
\text { HR (95\% CL) }\end{array}$ & $\mathrm{p}$ value & $\begin{array}{c}\text { Adjusted } \\
\text { HR (95\% CL) }\end{array}$ & $\mathrm{p}$ value \\
\hline \multicolumn{7}{|l|}{ Clinical outcomes (\%) } \\
\hline All-cause death & $26(1.8)$ & $46(3.9)$ & $2.15(1.33-3.48)$ & 0.002 & $2.21(1.29-3.80)$ & 0.004 \\
\hline Cardiac death & $15(1.0)$ & $25(2.1)$ & $2.03(1.07-3.84)$ & 0.031 & $2.01(1.01-3.99)$ & 0.046 \\
\hline Non cardiac death & $11(0.8)$ & $21(1.8)$ & $2.32(1.12-4.82)$ & 0.023 & $2.90(1.16-7.27)$ & 0.023 \\
\hline Recurrent MI & $7(0.5)$ & $9(0.8)$ & $1.56(0.58-4.18)$ & 0.380 & $1.33(0.42-4.22)$ & 0.630 \\
\hline Repeat PCI & $40(2.8)$ & $40(3.4)$ & $1.21(0.78-1.88)$ & 0.387 & $1.22(0.75-1.98)$ & 0.426 \\
\hline TLR & $11(0.8)$ & $11(0.9)$ & $1.21(0.52-2.79)$ & 0.656 & $1.17(0.43-3.18)$ & 0.754 \\
\hline TVR & $10(0.7)$ & $10(0.8)$ & $1.22(0.51-2.93)$ & 0.659 & $1.62(0.62-4.23)$ & 0.322 \\
\hline CABG & $4(0.3)$ & $2(0.2)$ & $0.61(0.11-3.31)$ & 0.564 & $0.48(0.05-4.82)$ & 0.530 \\
\hline MACE & $68(4.7)$ & $84(7.1)$ & $1.50(1.09-2.07)$ & 0.013 & $1.50(1.05-2.13)$ & 0.024 \\
\hline
\end{tabular}

Data are expressed as No. (\%) unless otherwise indicated.

CVA: cerebrovascular accident, Cl: confidence interval, CABG: coronary artery bypass graft, GFR: glomerular filtration rate, HR: hazard ratios, MI: myocardial infarction, MACE: major adverse cardiac events, PCI: percutaneous coronary intervention, TLR: target lesion revascularization, TVR: target vessel revascularization.

was no longer degraded within 1 year and the long-term clinical outcomes and mortality rates were better than those of patients with a degraded GFR (Fig. 2).

Multivessel PCI patients and IRA-only patients had similar results in terms of the 1-year creatinine and GFRrelated outcomes (increase by $0.9 \%$ and $0.7 \%$, respectively), indicating that the PCI method chosen is not related to changes in GFR. Alsadat et al. ${ }^{17}$ showed similar outcomes 

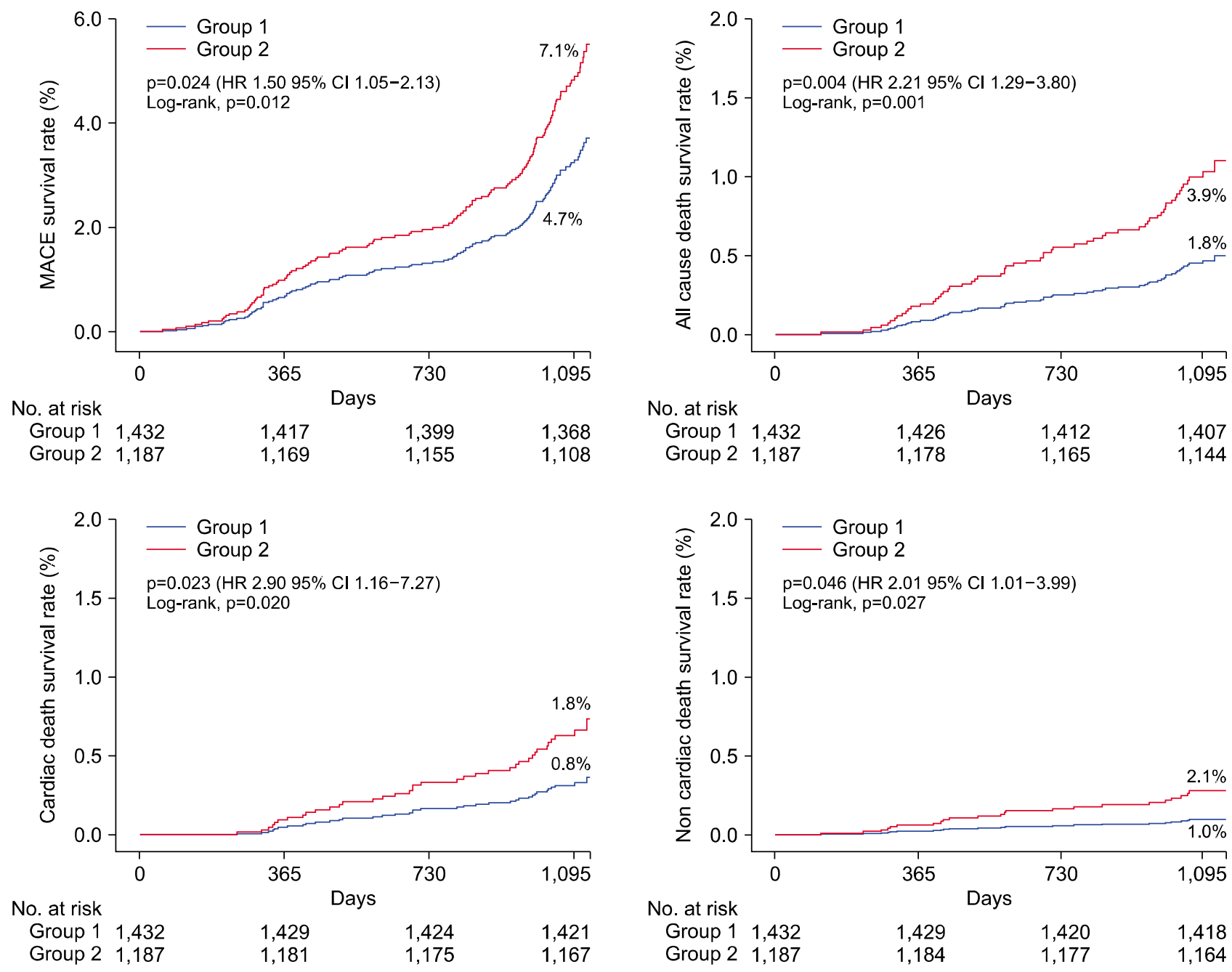

FiG. 2. Adjusted cumulative incidences of MACE, all-cause death, cardiac death and non-cardiac death in Kaplan-Meier analysis. MACE: major adverse cardiac events, CL: confidence interval, HR: hazard ratios.

TABLE 5. Multivariate analysis for predictors of after 1-year in patients with GFR $<60 \mathrm{~mL} / \mathrm{min} / 1.73 \mathrm{~m}^{2}$

\begin{tabular}{lcr}
\hline & \multicolumn{2}{c}{ Multivariate analysis } \\
\cline { 2 - 3 } & HR $(95 \% \mathrm{CL})$ & $\mathrm{p}$ values \\
\hline Age $\geq 65$ years & $2.43(1.82-3.25)$ & $<0.001$ \\
Men & $0.67(0.50-0.91)$ & 0.011 \\
Hypertension & $1.69(1.26-2.23)$ & $<0.001$ \\
Diabetes mellitus & $1.57(1.19-2.08)$ & 0.002 \\
Killip III/IV & $1.54(1.09-2.18)$ & 0.015 \\
Hb <10 g/dL & $2.45(1.71-3.50)$ & $<0.001$ \\
LVEF <40\% & $1.41(1.04-1.92)$ & 0.028 \\
Initial TIMI flow 0/1 & $0.74(0.58-0.94)$ & 0.013 \\
\hline
\end{tabular}

CL: confidence interval, GFR: glomerular filtration rate, HR: hazard ratios, Hb: hemoglobin, LVEF: left ventricular ejection fraction, TIMI: thrombolysis in myocardial infarction.
TABLE 6. Renal function laboratory characteristics of patients according to PCI strategies

\begin{tabular}{|c|c|c|c|}
\hline Variables & $\begin{array}{c}\text { Multivessel } \\
\text { PCI } \\
(\mathrm{n}=967)\end{array}$ & $\begin{array}{l}\text { IRA-only } \\
\text { PCI } \\
(\mathrm{n}=1652)\end{array}$ & $\mathrm{p}$ value \\
\hline \multicolumn{4}{|l|}{ Renal function laboratory } \\
\hline Creatinine, $\mathrm{mg} / \mathrm{dL}$ & $1.09 \pm 1.05$ & $1.09 \pm 0.96$ & 0.984 \\
\hline $\begin{array}{l}12 \mathrm{month} \mathrm{F} / \mathrm{U} \text { creatinine, } \\
\mathrm{mg} / \mathrm{dL}\end{array}$ & $1.11 \pm 0.98$ & $1.13 \pm 0.92$ & 0.711 \\
\hline $\mathrm{GFR}, \mathrm{mL} / \mathrm{min} / 1.73 \mathrm{~m}^{2}$ & $87.17 \pm 33.33$ & $85.77 \pm 32.11$ & 0.288 \\
\hline $\begin{array}{l}12 \text { month } \mathrm{F} / \mathrm{U} \text { GFR, } \mathrm{mL} / \\
\mathrm{min} / 1.73 \mathrm{~m}^{2}\end{array}$ & $81.98 \pm 27.87$ & $83.29 \pm 40.50$ & 0.372 \\
\hline $\mathrm{GFR}<60 \mathrm{~mL} / \mathrm{min} / 1.73 \mathrm{~m}^{2},(\%)$ & $175(18.1)$ & $305(18.5)$ & 0.816 \\
\hline $\begin{array}{l}12 \mathrm{month} \text { F/U GFR }<60 \mathrm{~mL} / \\
\mathrm{min} / 1.73 \mathrm{~m}^{2},(\%)\end{array}$ & $186(19.2)$ & $318(19.2)$ & 0.993 \\
\hline Delta GFR $\geq 0 \%$ & $67(36.0)$ & $104(32.7)$ & 0.448 \\
\hline
\end{tabular}

Data are expressed as No. (\%) unless otherwise indicated.

F/U: follow-up, GFR: glomerular filtration rate, IRA: infarct related artery, PCI: percutaneous coronary interventions. 
for multivessel PCI and IRA-only PCI in terms of CKD $(p=0.56)$. In the KAMIR-NIH data, creatinine levels were not statistically significantly different between the multivessel PCI group and the IRA-only PCI group. ${ }^{18}$ Our understanding of this area is still relatively lacking, and more studies are needed. In short, in our results, the two PCI methods in MVD patients have no effect on GFR prognosis.

The risk factors for a GFR $<60 \mathrm{~mL} / \mathrm{min} / 1.73 \mathrm{~m}^{2}$ in AMI with MVD patients after 1 year were age over 65 years, male sex, hypertension, diabetes mellitus, high Killip class, low hemoglobin, low LVEF, and slow TIMI flow. In the Choices for Healthy Outcomes in Caring for ESRD (CHOICE) study, a large percentage of incident dialysis patients had traditional risk factors for cardiovascular disease, including age, hypertension, diabetes mellitus, and low LVEF. ${ }^{19}$ Therefore, patients with chronic renal failure as well as those with end-stage renal disease are at higher risk for and have worse outcomes after AMI. ${ }^{13,16,20}$ These results are similar to ours except for male sex, Killip class, and TIMI flow. Moreover, smoking is associated with a markedly increased risk of cardiovascular diseases in CKD patients, ${ }^{21}$ but this factor was not assessed in this study.

Although delta GFR is not a commonly used indicator in the clinical setting, it can elucidate the trends in renal function. However, because creatinine level is a commonly used indicator, the delta GFR value can be calculated easily. Moreover, data regarding delta GFR in patients with AMI and MVD can help ascertain and develop more treatment options and methods to manage their conditions. This, in turn, can significantly reduce the mortality and cardiovascular event rates in this patient population. Conversely, this will place a great burden on the kidneys, ${ }^{22}$ and thus, the amount of contrast used during coronary angiography should be reduced. At the same time, attention must be paid to the patient's age, sex, blood pressure, and glucose and hemoglobin levels, which are risk factors for a low GFR.

There are several limitations to this study. First, it considered only patients with AMI and MVD using the outcomes of revascularization performed by a variety of cardiologists in major PCI centers in Korea. Second, the baseline creatinine level was only ascertained at arrival. However, this level is unstable, especially in AMI patients. It is uncertain whether the previous creatinine level is an indicator of chronic kidney injury or if acute kidney injury was caused by hemodynamic changes after AMI. The same current creatinine index is that after 1 year, and it was unclear whether the patients were cured of the kidney injury. Furthermore, creatinine or eGFR levels baseline should be equal and then delta GFR should be analyzed for cardiac outcomes after PCI. Third, we selected a very limited number of patients with MVD who underwent PCI. Thus, the results are not generalizable to all AMI patients, such as single-vessel disease patients. Fourth, we didn't exclude cardiac shock, CKD stage $>2$, or very old age patients. Finally, our database is at least 5 years old; thus, we need more recent and longer or real-time data to increase the strength of our findings.
In summary, the outcomes were better in the 3-year clinical follow-up analysis of better delta GFR patients with AMI and MVD who underwent PCI than in patients with a worse delta GFR. Delta GFR is an independent risk factor for MACE outcomes. Clinically, we should be more vigilant and closely observe the changes in AMI and MVD patients to monitor their renal function regardless of the PCI method used.

\section{ACKNOWLEDGEMENTS}

The authors thank the Korea Acute Myocardial Infarction Registry-National Institutes of Health (KAMIR-NIH) investigators: Myung Ho Jeong, MD; Youngkeun Ahn, MD; Sung Chul Chae, MD; Jong Hyun Kim, MD; Seung-Ho Hur, MD; Young Jo Kim, MD; In Whan Seong, MD; Donghoon Choi, MD; Jei Keon Chae, MD; Taek Jong Hong, MD; Jae Young Rhew, MD; Doo-Il Kim, MD; In-Ho Chae, MD; Jung Han Yoon, MD; Bon-Kwon Koo, MD; Byung-Ok Kim, MD; Myoung Yong Lee, MD; Kee-Sik Kim, MD; Jin-Yong Hwang, MD; Myeong Chan Cho, MD; Seok Kyu Oh, MD; Nae-Hee Lee, MD; Kyoung Tae Jeong, MD; Seung-Jea Tahk, MD; Jang-Ho Bae, MD; Seung-Woon Rha, MD; Keum-Soo Park, MD; Chong Jin Kim, MD; Kyoo-Rok Han, MD; Tae Hoon Ahn, MD; Moo-Hyun Kim, MD; Ki Bae Seung, MD; Wook Sung Chung, MD; Ju-Young Yang, MD; Chong Yun Rhim, MD; Hyeon-Cheol Gwon, MD; SeongWook Park, MD; Young-Youp Koh, MD; Seung Jae Joo, MD; Soo-Joong Kim, MD; Dong Kyu Jin, MD; Jin Man Cho, MD; Sang-Wook Kim, MD; Jeong Kyung Kim, MD; Tae Ik Kim, MD; Deug Young Nah, MD; Si Hoon Park, MD; Sang Hyun Lee, MD; Seung Uk Lee, MD; Hang-Jae Chung, MD; Jang-Hyun Cho, MD; Seung Won Jin, MD; Myeong-Ki Hong, MD; Yangsoo Jang, MD; Jeong Gwan Cho, MD; Hyo-Soo Kim, MD; and Seung Jung Park, MD.

The research was supported by a fund (2016-ER6304-02) by research of Korea centers for disease control and prevention.

\section{CONFLICT OF INTEREST STATEMENT}

None declared.

\section{REFERENCES}

1. Gibson CM, Dumaine RL, Gelfand EV, Murphy SA, Morrow DA, Wiviott SD, et al. Association of glomerular filtration rate on presentation with subsequent mortality in non-ST-segment elevation acute coronary syndrome; observations in 13,307 patients in five TIMI trials. Eur Heart J 2004;25:1998-2005.

2. Manjunath G, Tighiouart H, Ibrahim H, MacLeod B, Salem DN, Griffith JL, et al. Level of kidney function as a risk factor for atherosclerotic cardiovascular outcomes in the community. J Am Coll Cardiol 2003;41:47-55.

3. Polzin DJ. Chronic kidney disease in small animals. Vet Clin North Am Small Anim Pract 2011;41:15-30.

4. Fuster V. Global burden of cardiovascular disease: time to imple- 
ment feasible strategies and to monitor results. J Am Coll Cardiol 2014;64:520-2.

5. Watanabe H, Morimoto T, Shiomi H, Furukawa Y, Nakagawa Y, Ando K, et al. Chronic total occlusion in a non-infarct-related artery is closely associated with increased five-year mortality in patients with ST-segment elevation acute myocardial infarction undergoing primary percutaneous coronary intervention (from the CREDO-Kyoto AMI registry). EuroIntervention 2017;12:e187482.

6. Ahn SG, Lee JW, Kang DR, Kim HS, Go TH, Yu MH, et al. Immediate multivessel intervention versus culprit-vessel intervention only in patients with ST-elevation myocardial infarction and multivessel coronary disease: data from the prospective KAMIR-NIH registry. Coron Artery Dis 2019;30:95-102.

7. Jeong TD, Lee W, Chun S, Min WK. Association between the delta estimated glomerular filtration rate and the prevalence of monoclonal gammopathy of undetermined significance in Korean males. Biomed Res Int 2014;2014:356080.

8. Kim Y, Jeong MH, Ahn Y, Kim JH, Hong YJ, Sim DS, et al. Results of a 10-year experience in Korea using drug-eluting stents during percutaneous coronary intervention for acute myocardial infarction (from the Korea Acute Myocardial Infarction Registry). Am J Cardiol 2018;122:365-73.

9. Levey AS, Bosch JP, Lewis JB, Greene T, Rogers N, Roth D. A more accurate method to estimate glomerular filtration rate from serum creatinine: a new prediction equation. Modification of Diet in Renal Disease Study Group. Ann Intern Med 1999;130:461-70.

10. Blasco L, Sanjuan R, Carbonell N, Solís MA, Puchades MJ, Torregrosa I, et al. Estimated glomerular filtration rate in short-risk stratification in acute myocardial infarction. Cardiorenal Med 2011;1: 131-8.

11. Walsh CR, O'Donnell CJ, Camargo CA Jr, Giugliano RP, LloydJones DM. Elevated serum creatinine is associated with 1-year mortality after acute myocardial infarction. Am Heart J 2002; 144:1003-11.

12. Chobanian AV, Bakris GL, Black HR, Cushman WC, Green LA, Izzo JL Jr, et al. The Seventh Report of the Joint National Committee on Prevention, Detection, Evaluation, and Treatment of High Blood Pressure: the JNC 7 report. JAMA 2003;289:2560-72.

13. Anavekar NS, McMurray JJ, Velazquez EJ, Solomon SD, Kober
L, Rouleau JL, et al. Relation between renal dysfunction and cardiovascular outcomes after myocardial infarction. N Engl J Med 2004;351:1285-95.

14. Santopinto JJ, Fox KA, Goldberg RJ, Budaj A, Piñero G, Avezum A, et al. Creatinine clearance and adverse hospital outcomes in patients with acute coronary syndromes: findings from the global registry of acute coronary events (GRACE). Heart 2003;89:10038 .

15. Anavekar NS, Solomon SD, McMurray JJ, Maggioni A, Rouleau JL, Califf R, et al. Comparison of renal function and cardiovascular risk following acute myocardial infarction in patients with and without diabetes mellitus. Am J Cardiol 2008;101:925-9.

16. Shlipak MG, Heidenreich PA, Noguchi H, Chertow GM, Browner WS, McClellan MB. Association of renal insufficiency with treatment and outcomes after myocardial infarction in elderly patients. Ann Intern Med 2002;137:555-62.

17. Alsadat N, Hyun K, D'Souza M, Chew D, Weaver J, Juergens C, et al. Revascularization strategies in patients with STEMI: culprit-only vs multivessel revascularization using percutaneous coronary intervention. J Invasive Cardiol 2019;31:314-8.

18. Kim YH, Her AY, Jeong MH, Kim BK, Hong SJ, Kim JS, et al. Impact of stent generation on 2-year clinical outcomes in ST-segment elevation myocardial infarction patients with multivessel disease who underwent culprit-only or multivessel percutaneous coronary intervention. Catheter Cardiovasc Interv 2020;95:E4055.

19. Longenecker JC, Coresh J, Powe NR, Levey AS, Fink NE, Martin A, et al. Traditional cardiovascular disease risk factors in dialysis patients compared with the general population: the CHOICE Study. J Am Soc Nephrol 2002;13:1918-27.

20. Wright RS, Reeder GS, Herzog CA, Albright RC, Williams BA, Dvorak DL, et al. Acute myocardial infarction and renal dysfunction: a high-risk combination. Ann Intern Med 2002;137:563-70.

21. Shah DS, Polkinghorne KR, Pellicano R, Kerr PG. Are traditional risk factors valid for assessing cardiovascular risk in end-stage renal failure patients? Nephrology (Carlton) 2008;13:667-71.

22. Amin AP, Bach RG, Caruso ML, Kennedy KF, Spertus JA. Association of variation in contrast volume with acute kidney injury in patients undergoing percutaneous coronary intervention. JAMA Cardiol 2017;2:1007-12. 